\title{
Effects of an Overground Walking Program With a Robotic Exoskeleton on Long-Term Manual Wheelchair Users With a Chronic Spinal Cord Injury: Protocol for a Self-Controlled Interventional Study
}

Alec Bass ${ }^{1,2^{*}}$, PT, MSc; Mylène Aubertin-Leheudre ${ }^{3 *}, \mathrm{PhD}$; Claude Vincent ${ }^{4,5^{*}}, \mathrm{OT}, \mathrm{PhD}$; Antony D Karelis ${ }^{3^{*}}, \mathrm{PhD}$; Suzanne N Morin ${ }^{6 *}, \mathrm{MD}, \mathrm{MSc}$; Michelle $\mathrm{McKerral}^{7 *}$, NPsych, PhD; Cyril Duclos ${ }^{1,2^{*}}, \mathrm{PhD}$; Dany H Gagnon ${ }^{1,2^{*}}, \mathrm{PT}$, $\mathrm{PhD}$

\footnotetext{
${ }^{1}$ School of Rehabilitation, Faculty of Medicine, Université de Montréal, Montréal, QC, Canada

${ }^{2}$ Centre for Interdisciplinary Research in Rehabilitation of Greater Montreal, Centre Intégré Universitaire de Santé et Services Sociaux du Centre-Sud-de-l' ̂̂le-de-Montréal, Montréal, QC, Canada

${ }^{3}$ Department of Exercise Science, Université du Québec à Montréal, Montréal, QC, Canada

${ }^{4}$ Department of Rehabilitation, Faculty of Medicine, Université Laval, Québec, QC, Canada

${ }^{5}$ Centre for Interdisciplinary Research in Rehabilitation and Social Integration, Québec, QC, Canada

${ }^{6}$ Department of Medicine, McGill University, Montréal, QC, Canada

${ }^{7}$ Departement of Psychology, Faculty of Arts and Sciences, Université de Montréal, Montréal, QC, Canada

*all authors contributed equally
}

\section{Corresponding Author:}

Dany H Gagnon, PT, PhD

School of Rehabilitation

Faculty of Medicine

Université de Montréal

P.O. Box 6128, Station Centre-Ville, Pavillon 7077 Avenue du Parc - Office U-402-32

Montréal, QC, H3C 3J7

Canada

Phone: 15143436111 ext 26382

Email: dany.gagnon.2@umontreal.ca

\section{Abstract}

Background: In wheelchair users with a chronic spinal cord injury $\left(\mathrm{WU}_{\mathrm{SCI}}\right)$, prolonged nonactive sitting time and reduced physical activity - typically linked to this mode of mobility — contribute to the development or exacerbation of cardiorespiratory, musculoskeletal, and endocrine-metabolic health complications that are often linked to increased risks of chronic pain or psychological morbidity. Limited evidence suggests that engaging in a walking program with a wearable robotic exoskeleton may be a promising physical activity intervention to counter these detrimental health effects.

Objective: This study's overall goals are as follows: (1) to determine the effects of a 16-week wearable robotic exoskeleton-assisted walking program on organic systems, functional capacities, and multifaceted psychosocial factors and (2) to determine self-reported satisfaction and perspectives with regard to the intervention and the device.

Methods: A total of $20 \mathrm{WU}_{\mathrm{SCI}}$, who have had their injuries for more than 18 months, will complete an overground wearable robotic exoskeleton-assisted walking program (34 sessions; $60 \mathrm{~min} / \mathrm{session}$ ) supervised by a physiotherapist over a 16-week period (one to three sessions/week). Data will be collected 1 month prior to the program, at the beginning, and at the end as well as 2 months after completing the program. Assessments will characterize sociodemographic characteristics; anthropometric parameters; sensorimotor impairments; pain; lower extremity range of motion and spasticity; wheelchair abilities; cardiorespiratory fitness; upper extremity strength; bone architecture and mineral density at the femur, tibia, and radius; total and regional body composition; health-related quality of life; and psychological health. Interviews and an online questionnaire will be conducted to measure users' satisfaction levels and perspectives at the end of the program. Differences across measurement times will be verified using appropriate parametric or nonparametric analyses of variance for repeated measures. 
Results: This study is currently underway with active recruitment in Montréal, Québec, Canada. Results are expected in the spring of 2021.

Conclusions: The results from this study will be essential to guide the development, implementation, and evaluation of future evidence-based wearable robotic exoskeleton-assisted walking programs offered in the community, and to initiate a reflection regarding the use of wearable robotic exoskeletons during initial rehabilitation following a spinal cord injury.

Trial Registration: ClinicalTrials.gov NCT03989752; https://clinicaltrials.gov/ct2/show/NCT03989752

International Registered Report Identifier (IRRID)： DERR1-10.2196/19251

(JMIR Res Protoc 2020;9(9):e19251) doi: 10.2196/19251

\section{KEYWORDS}

assistive technology; locomotion; spinal cord injury; rehabilitation; robotics; osteoporosis

\section{Introduction}

\section{Deleterious Effects of Nonactive Sitting Time and Reduced Physical Activity}

Approximately 100,000 Canadians are currently living with a spinal cord injury (SCI) and nearly 4000 new cases are reported annually in Canada [1]. Individuals affected by an SCI usually experience sensory, motor, and autonomic impairments that challenge their walking and walking-related abilities. Despite intensive initial rehabilitation, regaining effective walking ability is challenging for most [2,3]. Indeed, many individuals will not regain their ability to walk due to trunk and lower extremity paralysis or severe paresis. For others, the cardiorespiratory, muscular, or balance requirements needed to walk are too great to achieve a sufficient distance $(\sim 183-677 \mathrm{~m})$ or velocity $(\sim 0.44-1.32 \mathrm{~m} / \mathrm{s})$ for ambulation within their home or in the community [4]. Hence, they will generally use a powered or manually propelled wheelchair as their main mode of mobility. The prolonged, nonactive sitting time [5] and the reduction or cessation of physical activity $[6,7]$ typically linked to this mode of mobility contribute to the development or exacerbation over time of complex and chronic secondary health problems. These health problems often effect the cardiorespiratory [8-12], musculoskeletal [13-17], and endocrine-metabolic [18-23] systems. Moreover, they are often coupled with raised risks of nociceptive or neuropathic pain [24,25] or psychological morbidity [26] (eg, increased depressive symptoms). In turn, these negatively affect functional skills and capacity as well as psychosocial factors in long-term wheelchair users with a chronic SCI ( $\mathrm{WU}_{\mathrm{SCI}}$ ) [27], while also increasing the risk of premature mortality and the burden on caregivers. It is no surprise that these impacts come with substantial financial costs, estimated to be between CAD \$1.5 million and \$3 million ( $\sim$ US \$1.1-\$2.3 million) per person with an SCI in the Canadian health care system [28].

\section{Inventory of Rehabilitation and Physical Activity Interventions}

Given the increased life expectancy owing to improvements in medical treatment, along with the growing population of individuals with SCI, there have been recent calls to direct additional attention to the cascade of cardiorespiratory, musculoskeletal, and endocrine-metabolic health problems faced by this population and to interventions targeting modifiable factors linked to these problems [29-31]. To date, most rehabilitation and physical activity interventional studies aiming to mitigate these health problems can be grouped within three main categories: (1) static standing activities using frames with or without full-body vibrations [32], (2) dynamic standing activities combining braces, body-weight support, functional electrical stimulation, or robotic exoskeleton systems for treadmill ambulation with various degrees of lower extremity weight bearing [33-36], and (3) lower extremity or trunk neuromuscular electrical stimulation for cycling or rowing in a sitting position $[37,38]$. Scoping and systematic reviews confirm that most of these interventions were tested among relatively small and heterogeneous samples of individuals with SCI over relatively short periods of time (ie, $\leq 12$ weeks) [30]. They also highlight that superiority, equivalence, and noninferiority trial designs have rarely been used and no clear consensus has yet emerged on the best possible interventions for a given individual at a specific time within the continuum of care [30]. Nonetheless, based on the currently available evidence, it is relatively well established among $\mathrm{WU}_{\mathrm{SCI}}$ that the following is true:

1. Gravity-derived high-standing loads, as well as impacts resulting even from low walking speeds [39], are the prominent sources of adaptive stimuli for bone health and surpass the effects linked to static standing or resistance training alone (eg, functional electrical stimulation) [40].

2. Two to three sessions per week of regular structured exercise at moderate-to-vigorous intensity for at least 20 minutes, plus upper body strength exercise (ie, three sets of 10 repetitions at $50 \%-80 \%$ of the one-repetition maximum for large muscle groups), improve cardiorespiratory and endocrine-metabolic health [41-43]. Increasing this exercise intensity is expected to potentiate these beneficial effects [44].

\section{Wearable Robotic Exoskeletons as a Promising Intervention}

Commercially available wearable robotic exoskeletons, an assistive technology allowing $\mathrm{WU}_{\mathrm{SCI}}$ to stand and walk overground (see Figure 1), now offer opportunities for clinicians and scientists to develop novel activity-based physical activity programs articulated around overground walking and walking-related abilities $[45,46]$. Though only small-scale studies are currently available, including a feasibility study from our lab, with most focusing on walking performance [45-54], emerging evidence suggests that performing sit-stand transfers, 
standing, and walking with a wearable robotic exoskeleton promote lower extremity mechanical loading and mobility. The gravity exposure and muscle elongation-relaxation cycles at the lower extremities signal the mechanosensitive osteocytes and regulate the bone remodeling process via bone formation and reabsorption (ie, mechanotransduction process) [55]. Additionally, the performance of these functional abilities with a wearable robotic exoskeleton solicits the large trunk, thoracohumeral, and upper extremity muscles [56] (ie, strengthening exercise) via three mechanisms: (1) maintenance of standing balance, which is even more difficult as the center of mass is moved upward and backward given the configurations of the wearable robotic exoskeleton, (2) control of anterolateral body-weight shifts required to safely initiate the steps, and (3) unloading lower extremities to smooth heel contact with the ground at heel strike. Walking with a wearable robotic exoskeleton also increases the energy expenditure need (ie, aerobic exercise) [57-59]. By coupling these types of exercises, walking with a wearable robotic exoskeleton may lead to beneficial cardiorespiratory, musculoskeletal, and endocrine-metabolic $[60,61]$ adaptations in $\mathrm{WU}_{\mathrm{SCI}}$. In addition, a growing body of evidence suggests that cognitive and executive [62] as well as psychological $[63,64]$ benefits can be anticipated, as favorable associations with physical activity, especially aerobic exercise, have been documented. Also of interest, $\mathrm{WU}_{\mathrm{SCI}}$ have expressed high levels of satisfaction with wearable robotic exoskeleton-assisted walking programs and have positively perceived the wearable robotic exoskeleton learnability and usability [64]. To what extent these health benefits may have positive synergistic effects on their functional capacities and psychosocial well-being is unclear. How to best configure wearable robotic exoskeleton-assisted walking programs (eg, number, frequency, duration, and intensity of sessions) while conciliating them with the perspectives of $\mathrm{WU}_{\mathrm{SCI}}$ to potentiate the outcomes of such programs also remains elusive.

Figure 1. Wearable robotic exoskeleton for sit-stand transitions and overground walking manufactured by Ekso Bionics.

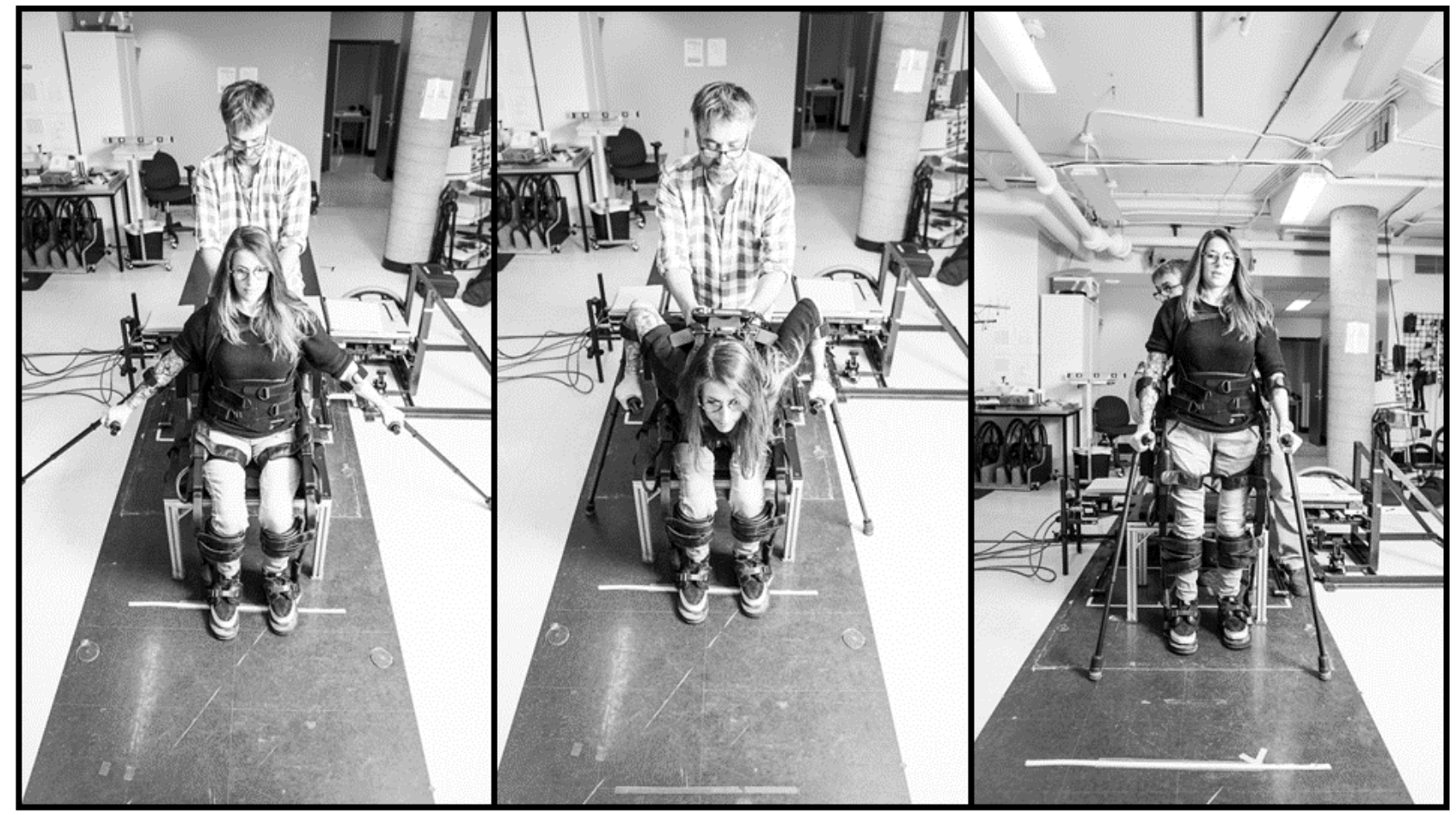

\section{Objectives}

The overall goals of this study, using mixed methods, are as follows: (1) to determine the immediate and short-term effects of a 16-week overground wearable robotic exoskeleton-assisted walking program on organic systems, functional capacities, and multifaceted psychosocial factors among $\mathrm{WU}_{\mathrm{SCI}}$ living in the community, and (2) to determine self-reported satisfaction and perspectives with regard to the intervention and the device. The specific objectives are articulated around four research questions and hypotheses:

1. Question 1: Does a 16-week walking program with the wearable robotic exoskeleton induce beneficial changes on musculoskeletal, cardiorespiratory, and endocrine-metabolic health; wheelchair-related functional skills and mobility; and psychosocial outcomes? Hypothesis 1: It is hypothesized that beneficial effects observed during the postintervention and retention measurement times will significantly and meaningfully exceed any changes observed during the control and preintervention measurement times (ie, $\mathrm{T}_{0}$ [control measurement time] vs $\mathrm{T}_{1}$ [preintervention measurement time] vs $\mathrm{T}_{2}$ [postintervention measurement time] vs $\mathrm{T}_{3}$ [retention measurement time]).

2. Question 2: What personal factors best determine and predict the beneficial effects of the walking program with the wearable robotic exoskeleton? Hypothesis 2: It is hypothesized that the individuals with the highest level of SCI and the longest time since the SCI (ie, possibly the best determinants and predictors) will be those who respond best to the walking program. 
3. Question 3: What program attributes best determine and predict the beneficial effects of the walking program with the wearable robotic exoskeleton? Hypothesis 3: It is hypothesized that the total number of steps taken will be the best determinant and predictor of the measured changes.

4. Question 4: What are the participants' satisfaction levels with the walking program and the wearable robotic exoskeleton itself, and what are the expectations regarding its future use in the context of a home- or community-based adapted physical activity program? Hypothesis 4: It is hypothesized that $\mathrm{WU}_{\mathrm{SCI}}$ will (1) express high levels of satisfaction with the walking program using the wearable robotic exoskeleton and with the wearable robotic exoskeleton itself and (2) report on how they envision its future in the context of home- or community-based use to shape the development of an adapted physical activity program in the future.

\section{Methods}

\section{Study Design}

A prospective, longitudinal, self-controlled interventional study with multiple discrete measurement times will be used to assess outcomes at baseline (ie, preintervention phase), during the intervention, and thereafter (ie, retention phases) (see Figure 2). While this design may contrast with classic study designs frequently recommending a separate comparison group to assess efficacy or effectiveness, the use of a separate comparison group was judged as nonideal in the context of this study, based on the challenges linked to the classification and quantification of the severity of SCIs and their heterogeneous consequences [65]. In addition, interventional trials of new technologies document that potential participants are reluctant to participate, refuse to adhere to the requirements of a control group, or withdraw for the most part from a control group $[66,67]$. To strike an optimal balance between the need to have a control group with the anticipated strong desire of potential participants to engage in the wearable robotic exoskeleton-assisted walking program, while also considering the amount of, and timeline limits linked to, the study's funding, the study includes a 4-week observation phase prior to the start of the intervention. Since only individuals with a chronic SCI with stable overall health status and life habits will be recruited, outcome measures will be assessed at the start and at the end of the 4-week observation phase. These outcome measures will provide data about each participant's natural variability and will enable us to detect whether the intervention has an effect greater than the underlying natural variability (ie, patient-specific minimal detectable change criteria computed); they will also enable us to test the effects of the intervention (ie, pre- vs postintervention responses). This boosts the ethical acceptability of the project, minimizes the impacts of potential and unmeasured confounding variables, facilitates recruitment, and mitigates the risk of experimental attrition. Lastly, semistructured interviews and an online questionnaire will capture participants' satisfaction levels and perspectives about the wearable robotic exoskeleton-assisted walking program and the mobility technology in itself (ie, the wearable robotic exoskeleton).

Figure 2. Summary of the design of the study along with the different assessment times. $\mathrm{T}_{0}$ : control measurement time; $\mathrm{T}_{1}$ : preintervention measurement time; $\mathrm{T}_{2}$ : postintervention measurement time; $\mathrm{T}_{3}$ : retention measurement time.

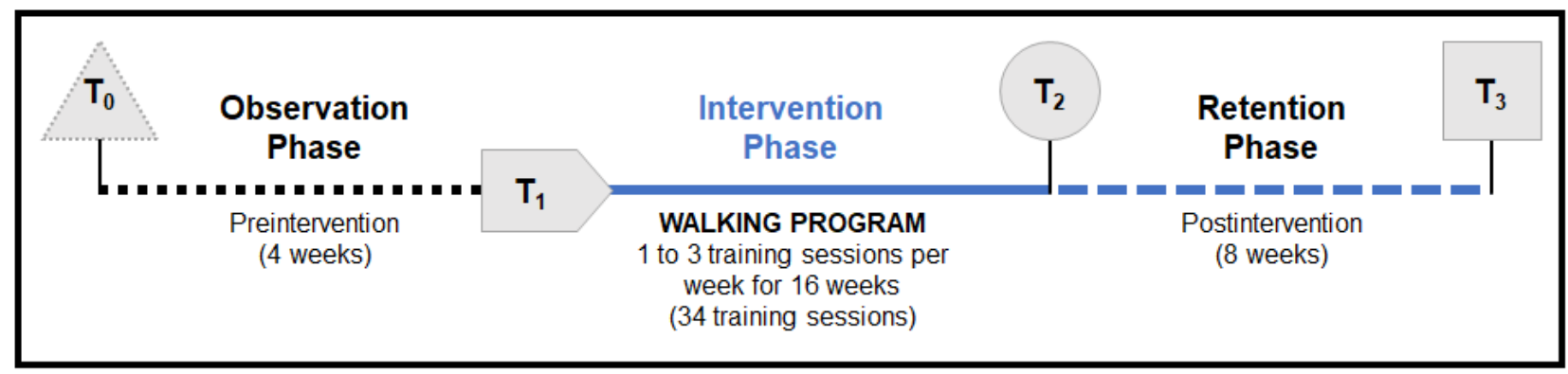

\section{Participants and Inclusion and Exclusion Criteria}

We aim to recruit a nonprobabilistic consecutive sample of 20 long-term $\mathrm{WU}_{\mathrm{SCI}}$. The inclusion and exclusion criteria are listed in Textbox 1. Initial screening is conducted by phone to establish eligibility based on criteria developed during the feasibility study. Once deemed eligible from the initial clinical screening, potential participants attend a short assessment to confirm eligibility. 
Textbox 1. Inclusion and exclusion criteria.

Participant-specific inclusion criteria:

- $\quad$ Adults $(\geq 18$ years old $)$

- Chronic complete or incomplete traumatic or nontraumatic spinal cord injury (SCI) at least 18 months before enrollment

- Long-term manual wheelchair use as primary means for in-house and community mobility (ie, nonambulatory)

- Understand and communicate in English or French

- Reside or will arrange for temporary housing in the community within $75 \mathrm{~km}$ from the main research site

Participant-specific exclusion criteria:

- Other neurological impairments aside from those linked to the SCI (eg, multiple sclerosis)

- Concomitant or secondary musculoskeletal impairments (eg, hip heterotopic ossification)

- History of lower extremity fracture within the past year

- Unstable cardiovascular or autonomic system

- Renal insufficiency

- Pregnancy

- Any other conditions that may preclude lower extremity weight-bearing, walking, or exercise tolerance in the wearable robotic exoskeleton

Exoskeleton-specific inclusion criteria:

- $\quad$ Body mass: $\leq 100 \mathrm{~kg}$

- Height: $1.52-1.93 \mathrm{~m}$

- $\quad$ Pelvis width: $30-46 \mathrm{~cm}$

- $\quad$ Thigh length: $51.0-61.4 \mathrm{~cm}$

- $\quad$ Lower leg length: $48.0-63.4 \mathrm{~cm}$

Exoskeleton-specific exclusion criteria:

- Inability to sit with hips and knees at $\geq 90^{\circ}$ flexion

- Lower extremity passive range of motion limitations (hip flexion contracture $\geq 5^{\circ}$, knee flexion contracture $\geq 10^{\circ}$, and ankle dorsiflexion $\leq-5^{\circ}$ with knee fully extended)

- Moderate-to-severe lower extremity spasticity (score of $>3$ on the Modified Ashworth Scale)

- Length discrepancy ( $\geq 1.3 \mathrm{~cm}$ or $\geq 1.9 \mathrm{~cm}$ at the thigh or lower leg segment, respectively)

- Skin integrity issues preventing wear of the wearable robotic exoskeleton

\section{Intervention: Overground Wearable Robotic Exoskeleton-Assisted Walking Program}

An Ekso GT (Ekso Bionics) wearable robotic exoskeleton, which has been approved by Health Canada, is used in this study (see Figure 1). At $T_{1}$, participants engage in a wearable robotic exoskeleton-assisted overground walking program that encompasses 34 training sessions offered over a 16-week period. The number of training sessions per week progressively increases to safely and efficiently adhere to the overload principle (see Figure 3). The duration of the training program mimics that of a recent study that confirms for the first time an improvement in bone turnover among individuals with a chronic
SCI following a 16-week walking program [39]. The frequency of the training program that progresses from one to three sessions per week matches the latest recommendation from the Physical Activity Guidelines for Adults with SCI, including the new conditional recommendation to engage in at least 30 minutes of moderate-to-vigorous intensity aerobic exercise three times per week for cardiometabolic health benefits [68]. All training sessions are supervised by a certified physiotherapist as well as a physiotherapy assistant as needed [46,53]. During each 60-minute training session, participants perform sit-stand transfers and walk with the wearable robotic exoskeleton and a walking aid (ie, rolling walker or forearm crutches). Verbal and tactile feedback are provided by the physiotherapist as needed. 
Figure 3. Progression of the number of training sessions per week during the 16-week walking program.

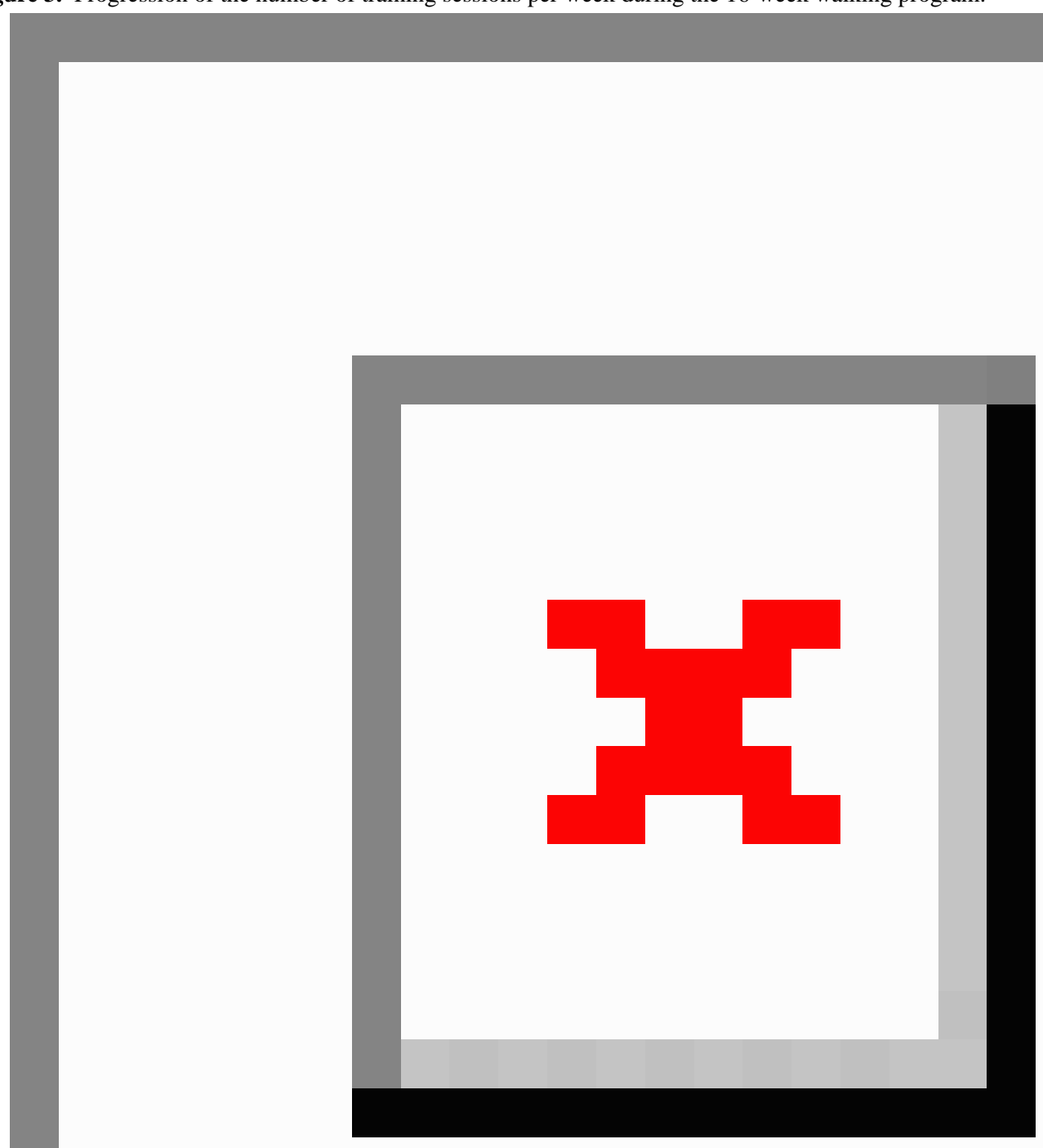

Total hip areal bone mineral density (aBMD), determined with dual-energy x-ray absorptiometry (DXA) scans performed at $\mathrm{T}_{1}$, is used to assign each participant to one of three training regimes based on lower extremity fracture risks [69]: (1) conservative (T-score $\leq-2.5$; first session includes a maximum of 300 steps; number of steps progresses up to $10 \%$ every week), (2) moderate $(-2.5<\mathrm{T}$-score $<-1.0$; first session includes a maximum of 400 steps; number of steps progresses up to $15 \%$ every week), or (3) aggressive (T-score $\geq-1.0$; first session includes a maximum of 500 steps; number of steps progresses up to $20 \%$ every week). Workload is further individualized depending on each participant's level of proficiency and tolerance; it is progressively and safely increased by modifying walking parameters (eg, number of steps, speed, and duration) or reducing total resting time or level of assistance provided by the physiotherapist to maintain a moderate-to-vigorous training intensity (ie, rate of perceived exertion $\geq 3 / 10$ on the Modified Borg Scale [70]). Training parameters are recorded at the end of each session (eg, total standing time, total walking time, total number of steps, assistance provided, and rate of perceived exertion). Given the risks of adverse events inherently linked to the use of a wearable robotic exoskeleton [69,71], skin integrity at interface pressure points, particularly at the tibial tuberosity, and signs of inflammation at the ankle and knee joints before and after each training session, respectively, are assessed and any serious adverse events will be reported.

To be considered as having successfully completed the program, at least $75 \%$ of the training sessions (ie, 26/34) need to have 
been completed. To this effect, to assure an optimal attendance rate similar to the one reached during the feasibility study (ie, attendance rate was $97.7 \%$ ) [72] and to overcome one of the most commonly reported barriers to intervention studies (ie, transportation), participants have three key options: (1) driving their own car or being transported by car by a family member or a friend with free parking provided within 50 meters from the entrance, (2) using public transit, or (3) scheduling trips with the adapted transport free services.

\section{Outcomes: Domains, Tools, Measures, and Assessment Times}

\section{Overview}

All outcomes reflecting the potential impacts of the intervention based on the logic model (see Figure 4) are prospectively collected at $T_{0}, T_{1}, T_{2}$, and $T_{3}$, except the participants' satisfaction levels and perspectives and the endpoint interviews, which are only completed at $\mathrm{T}_{2}$. Outcomes are collected by a registered physiotherapist $(\mathrm{AB})$ who has been trained with standardized data collection protocols adapted for $\mathrm{WU}_{\mathrm{SCI}}$. All selected outcomes are commonly used in clinical trials targeting similar domains and populations-most have been used in the feasibility study_and most are summarized, including psychometric properties, and are recommended by well-established medical, rehabilitation, or psychosocial research organizations and networks [73]. A summary of all outcomes included in this study and the times at which they are administered is provided in Table 1 . The following subsections describe all outcomes in detail.

Figure 4. Project-specific logic model highlighting the relationships between the different domains of interest and related outcome measures. L/E: lower extremity; SCI: spinal cord injury; U/E: upper extremity; WRE: wearable robotic exoskeleton.

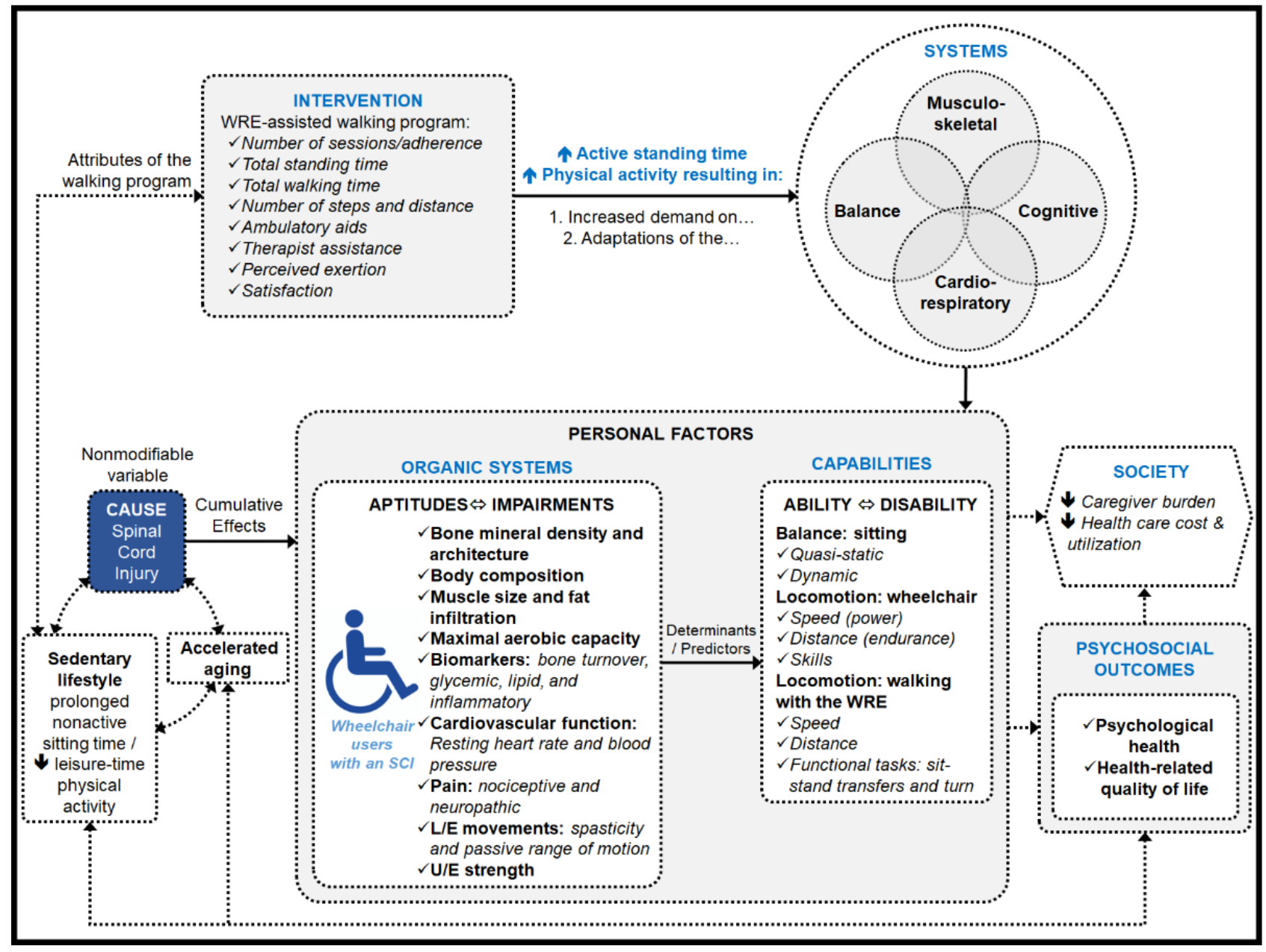


Table 1. Summary of outcomes.

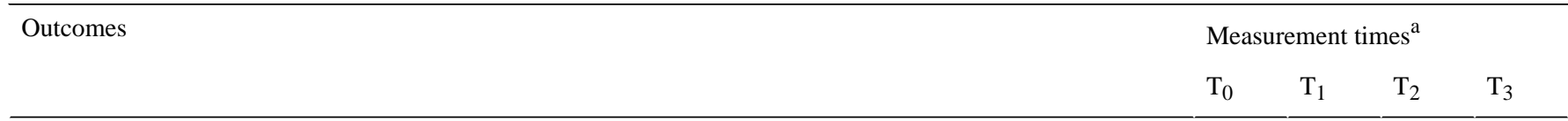

\section{Clinical assessments}

\section{Personal characteristics}

Sociodemographic characteristics (age, sex, etc)

Neurological impairment (American Spinal Injury Association Impairment Scale)

Anthropometric parameters (weight and height)

Resting heart rate and blood pressure

Pain (International SCI [spinal cord injury] Pain Basic Dataset version 2.0)

Passive range of motion at the ankle, knee, and hip joints (two-axis goniometer)

Spasticity (Modified Ashworth Scale)

\section{Wheelchair abilities}

20-meter wheelchair propulsion test (natural and maximal speeds)

Slalom test

6-minute manual wheelchair propulsion test

\section{Laboratory assessments}

Bone mineral density and architecture

Dual-energy x-ray absorptiometry (hip and lumbar vertebrae)

Peripheral quantitative computed tomography (proximal tibia, distal femur, and proximal radius)

\section{Body composition}

Dual-energy x-ray absorptiometry (total body)

\section{Muscle quality}

Peripheral quantitative computed tomography (intramuscular fat infiltration)

\section{Blood biomarkers}

Bone turnover (serum procollagen type $1 \mathrm{~N}$-terminal peptide, osteocalcin, C-terminal cross-linking telopeptide, and 25-hydroxyvitamin D)

Glycemia (fasting glucose, insulin, and glycosylated hemoglobin)

Insulin resistance (homeostatic model assessment)

Lipids (total cholesterol, high-density lipoprotein, low-density lipoprotein, triglycerides, and apolipoprotein B)

Inflammation (C-reactive protein, tumor necrosis factor alpha, interleuken-6, and interleuken-10)

\section{Cardiorespiratory fitness}

Respiratory gas analysis during 6-minute manual wheelchair propulsion test

Total distance travelled during the 6-minute manual wheelchair propulsion test

\section{Take-home assessments}

\section{Psychological health}

World Health Organization Quality of Life assessment

Beck Depression Inventory

Beck Anxiety Inventory

Psychological General Well-Being Index

\section{Participant satisfaction and perspectives}

Updated version of the Montreal Walking Exoskeleton Satisfaction and Perspectives Questionnaire Semistructured interview 
${ }^{\mathrm{a}}$ Measurement times: $\mathrm{T}_{0}$ (control measurement time), $\mathrm{T}_{1}$ (preintervention measurement time), $\mathrm{T}_{2}$ (postintervention measurement time), and $\mathrm{T}_{3}$ (retention measurement time).

\section{Clinical Assessments}

\section{Personal Characteristics}

Assessments are completed at the different assessment times to collect outcomes characterizing the following:

1. Sociodemographic characteristics (eg, age; sex; time since injury; history of fragility fracture; medications, including opioid analgesia, benzodiazepines, or unfractionated heparin; current smoking status; and alcohol intake) [74].

2. Neurological impairment (eg, American Spinal Injury Association Impairment Scale for neurological level, motor and sensory scores, and severity) [75].

3. Anthropometric parameters (eg, weight and height).

4. Resting heart rate and systolic and diastolic blood pressure using an electronic sphygmomanometer machine [76].

5. Pain using the International SCI Pain Basic Dataset version 2.0, which includes a set of core questions for up to three separate pain problems experienced over the past week and three questions on perceived pain interference with activities, mood, and sleep [77].

6. Passive range of motion at the ankle, knee, and hip joints with a two-axis goniometer (ie, contracture).

7. Upper extremity muscle strength (ie, pushing and pulling strength with a wheelchair wheel attached to an instrumented dynamometer and handgrip strength with a handheld dynamometer).

8. Lower extremity spasticity using the Modified Ashworth Scale [78].

\section{Wheelchair Abilities}

Wheelchair abilities are assessed using the following performance-based wheelchair propulsion tests: (1) 20-meter wheelchair propulsion test (natural and maximal speeds), (2) slalom test, and (3) 6-minute manual wheelchair propulsion test [79-82]. The slalom test is used as a surrogate of trunk control since forward reaching distance is a good determinant $(r=-0.75)$ [80] and trunk control is known to be the best predictor of multidirectional seated limits of stability during reaching $\left(R^{2}=0.95\right)$ [83]. The Wheelchair Skills Test Questionnaire version 5.0 [84] is used as well to assess wheelchair abilities. This questionnaire assesses 34 wheelchair mobility and wheelchair-related skills. Each skill is rated on a 4-point self-reported scale: responses to the question Can you do it? include 0 (no), 1 (partially), 2 (yes), and 3 (very well). A capacity score is calculated $(0 \%-100 \%)$, reflecting the number of skills that can be partially or completely done. Moreover, it assesses how confident-How confident are you? 0 (not at all), 1 (partly), 2 (moderately), or 3 (very)—and how often-How often do you do it? 0 (never), 1 (occasionally), 2 (usually), or 3 (always) — each skill is performed to calculate confidence and performance scores $(0 \%-100 \%)$.

\section{Laboratory Assessments}

\section{Bone Mineral Density and Architecture}

A DXA system (Lunar Prodigy, GE Healthcare) is used to calculate aBMD at the hip, femoral neck, and the first to the fourth lumbar vertebrae [85]. Moreover, T-scores compare the measured aBMD values of each participant against values predicted from a matched reference group for sex, age, and ethnicity and are expressed as the number of SDs (ie, z scores or T-scores depending on age of participant). Measurements of aBMD and $\mathrm{z}$ scores or T-scores are directly provided by the system's software.

In addition, a peripheral quantitative computed tomography (pQCT) system (XCT 3000, Stratec Biomedical Systems) is used to characterize the volumetric bone mineral density (vBMD) and the microarchitecture parameters of trabecular and cortical bones at various imaging sites: $66 \%$ of the tibia, $25 \%$ of the femur, and $66 \%$ of the radius. These sites were chosen to maximize muscle circumference in each scan [86]. To minimize site-selection error between measurement times, images are taken using a standardized protocol including scout views with recommended reference lines [86]. As per current recommendations, reported $\mathrm{pQCT}$ outcomes will minimally include the following: total trabecular and cortical mineral content; cortical cross-sectional area and thickness; and biomechanical strength indices calculated from density and area (ie, bone strength indices, polar section modulus, and polar strength strain index) [86]. Outcomes are calculated using a validated open source image analysis software package (Fiji distribution of ImageJ) $[87,88]$.

\section{Body Composition}

Whole-body scans obtained with the DXA system are used to quantify total and regional (ie, upper extremities, trunk, and lower extremities) body fat and fat-free (ie, lean) tissue mass and relative percentages, respectively [89]. These measures are directly provided by the DXA system's software.

\section{Muscle Quality}

Cross-sectional images of the femur, tibia, and radius captured with the pQCT system are also used to measure the muscle size (ie, cross-sectional area) and intramuscular fat infiltration (ie, muscle density) using the same validated open source image analysis software $[87,88]$.

\section{Blood Biomarkers}

Fasting blood samples (ie, >8-hour fast) are used to quantify bone turnover biomarkers (ie, serum procollagen type 1 $\mathrm{N}$-terminal peptide, osteocalcin, C-terminal cross-linking telopeptide, and 25-hydroxyvitamin D), glycemic biomarkers (ie, fasting glucose, insulin, and glycosylated hemoglobin), insulin resistance biomarkers (ie, homeostatic model assessment), lipid biomarkers (ie, total cholesterol, high-density lipoprotein, low-density lipoprotein, triglycerides, and apolipoprotein B), and inflammatory biomarkers (ie, C-reactive protein, tumor necrosis factor alpha, interleuken-6, and interleuken-10). 


\section{Cardiorespiratory Fitness}

At $\mathrm{T}_{1}$ and $\mathrm{T}_{2}$, participants complete the 6-minute manual wheelchair propulsion test wearing a gas analyzer system (COSMED K4b2, COSMED srl). This portable system incorporates a sealed face mask placed over the mouth and nose and anchored around the head, a telemetric stationary $\mathrm{O}_{2}$ and $\mathrm{CO}_{2}$ gas analyzing unit, and a battery harnessed to the anterior and posterior thorax. This system is calibrated before each test as recommended by the manufacturer. For the other two measurement times (ie, $\mathrm{T}_{0}$ and $\mathrm{T}_{3}$ ), the total distance travelled during the 6-minute manual wheelchair propulsion test is used as a surrogate measure of cardiorespiratory fitness since it has been found to strongly correlate and agree with the maximal arm-crank test ( $r=0.92$; mean difference $0.21 \pm 1.94 \mathrm{~mL} / \mathrm{kg} \cdot \mathrm{min}$ ) [90].

\section{Take-Home Assessments}

\section{Psychological Health}

For the psychosocial outcomes, health-related quality of life is measured with the short version of the World Health Organization Quality of Life assessment [91-94]. This includes 24 questions organized around four domains: physical health (seven items), psychological health (six items), social relationships (three items), and environment (eight items). There are two additional questions on overall health-related quality of life and general health. Each question is rated on a 5-point Likert interval scale ranging from 1 (poor) to 5 (good). At the end, scores for each question and a mean score computed for each domain are reported. To further investigate psychosocial outcomes, the Beck Depression Inventory [95], the Beck Anxiety Inventory [96], and the Psychological General Well-Being Index are used [97-99]. The Beck Depression Inventory and the Beck Anxiety Inventory are each comprised of 21 groups of statements that are evaluated on 4-point Likert scales, with higher scores indicating higher depressive or anxiety-related symptoms, respectively. The Psychological General Well-Being Index includes 22 items organized around components of psychological well-being, such as anxiety, positive well-being, self-control, depression, and general health and vitality. Response options for each item are individualized according to the given affective experience. Intensity or frequency of experience during the past month is rated on a 6-point Likert scale ranging from 0 (most negative option) to 5 (most positive option).

\section{Participant Satisfaction and Perspectives}

For participant satisfaction, an updated version of the Montreal Walking Exoskeleton Satisfaction and Perspectives Questionnaire (MWESP-Q) is completed online at $\mathrm{T}_{2}$. This questionnaire includes 54 statements that are organized around seven key domains: overall satisfaction related to the training program (two statements); satisfaction related to the overground robotic exoskeleton (seven statements); perceived learnability (12 statements); satisfaction related to the program attributes (eight statements); perceived health benefits (12 statements), including sentences that relate to pain, spasticity, bowel functions, and sleep; perceived risks and fears (11 statements); and perceived motivation to engage in regular physical activity (two statements). Each statement is rated using a 7-point Likert scale ranging from 1 (most negative option; eg, strongly disagree) to 7 (most positive option; eg, strongly agree) [64].

For participants' perspectives, a 20-30-minute semistructured interview is conducted over the phone to capture their general experience when participating in the wearable robotic exoskeleton-assisted training program. The interviews also serve as a platform for documenting participants' perspectives on the future of wearable robotic exoskeleton technology. To do so, various themes are discussed: potential benefits and recommendations for wearable robotic exoskeleton-assisted walking during the acute and subacute phases following spinal cord injury (eg, timing and conditions) or in a clinical setting during the chronic phase; opportunities for improvement (eg, functionality and structural aspects of the wearable robotic exoskeleton); and recommendations for a future home- or community-based wearable robotic exoskeleton-assisted walking program (eg, stairs, different surfaces, donning and doffing the wearable robotic exoskeleton without assistance, and operating the wearable robotic exoskeleton without assistance). The research professional who conducts these interviews has never met the participants and is not a member of the research team. All interviews are recorded to later enable verbatim transcription.

\section{Statistics}

\section{Sample Size Estimation}

The sample size estimate was based on a comparison using the variability of the absolute change (ie, mean \pm SD) in both body composition and bone mineral density (ie, main outcomes) measured pre- and postintervention in our preliminary study [61] and computed with a computerized sample size calculator [100]. Considering the self-controlled design of the study, a total of 18 participants are required to have an $80 \%$ chance of detecting a significant increase at the 5\% level in the leg lean body mass $(\mathrm{kg})$ at the tibia measured by DXA from 14.0 to 15.8 $\pm 2 \mathrm{mg} / \mathrm{cm}^{3}$ [61]. Likewise, a total of 18 participants are required to have an $80 \%$ chance of detecting a significant increase at the $5 \%$ level in the bone mineral density $\left(\mathrm{mg} / \mathrm{cm}^{3}\right)$ at the tibia measured by pQCT from 466 to $532 \pm 70 \mathrm{mg} / \mathrm{cm}^{3}$ [61]. Considering the dropout rate of $7.1 \%$ found during the feasibility study [46], an additional 2 participants were added for a total sample size of 20 participants.

\section{Quantitative and Qualitative Analyses}

Descriptive statistics (eg, mean, SD, and 95\% confidence interval) will be calculated for data summarizing sociodemographic characteristics as well as clinical and laboratory outcomes collected at the different measurement times. The normality of all data distributions and the absence of outliers will be verified via the Shapiro-Wilk test of normality and the absence of studentized residuals greater than \pm 3 SDs, respectively. Whenever applicable, the level of significance will be set at $P \leq .05$ for all statistical tests and the data will be analyzed using SPSS, version 25.0 (IBM Corp).

For Hypothesis 1, one-way analysis of variance for repeated measures (ie, normally distributed continuous data) or Freidman 
tests (ie, non-normally distributed continuous or categorical data) with planned comparisons based on the hypothesis and Bonferroni correction will be conducted to detect significant time effects, with a special interest for the preintervention $\left(\mathrm{T}_{0}\right.$ vs $\left.T_{1}\right)$, intervention $\left(T_{1}\right.$ vs $\left.T_{2}\right)$, and retention $\left(T_{2}\right.$ vs $\left.T_{3}\right)$ phases. In accordance with the principles of a classic intention-to-treat approach, all participants will be included in the final analyses, regardless of withdrawal, compliance, or unintentional missing data. For missing data, imputation of the mean value for the specific group at the specific assessment time will be used. Per-protocol exploratory analyses will also be performed comparing outcomes for those with walking program compliances of greater than $75 \%$ to examine maximum treatment efficacy.

For Hypotheses 2 and 3, Pearson or Spearman correlation coefficients will investigate the strength and direction of the relationships between the overall observed changes $\left(\left[\mathrm{T}_{1}-\mathrm{T}_{2}\right] /\right.$ $\mathrm{T}_{1} \times 100$ ) for each personal factor (ie, dependent variable) and the program characteristics (ie, independent variable). Independent variables having reached a critical threshold $(P \leq .25)$ will then be confronted in a stepwise multiple linear regression analysis to identify the three best predictors for each dependent variable and the coefficient of determination $\left(R^{2}\right)$ of the model. To determine the factors for identifying the best responders to the program, analyses similar to the previous ones will be completed, except that the independent variables will be sociodemographic characteristics, anthropometric parameters, characteristics of the SCI, personal factors, and functional disability.

For Hypothesis 4, using Microsoft Excel, descriptive statistics of the 54 statements (ie, mean, median, and SD) will summarize the results of the satisfaction survey (ie, the MWESP-Q). Audio recordings of the interviews will be transcribed verbatim using Microsoft Word. A summer research intern will read the transcripts and generate initial codes or subthemes. A co-codification of the first transcript will be done manually on printed paper with the list of initial codes and subthemes; this will be done independently by three research collaborators (ie, a summer research intern, a doctoral student, and a researcher who is a member of the research team). They will write codes directly in the margin of the printed transcripts. They will then meet via audio and video conferencing to compare and review coding, discuss discrepancies, and modify codes if necessary. This process will be done twice with the transcripts of the first two participants. To start the computerized qualitative analysis, all transcripts will be interpreted using thematic content analysis, where narrative data will be thematically coded and appraised using NVivo 10 (QSR International). A final report, integrating findings from the MWESP-Q and the interviews, will be produced and recommendations will be incorporated in order to shape the development of a future home- or community-based adapted physical activity program.

\section{Results}

This study was recently initiated at the Laboratoire de pathokinésiologie of the Centre de recherche interdisciplinaire en réadaptation du Montréal métropolitain (CRIR), Québec, Canada, which is part of the Centre intégré universitaire de santé et de services sociaux du Centre-Sud-de-l'Ile-de-Montréal in Montreal, Canada, and at the Laboratoire du muscle et de sa fonction of the Université du Québec à Montréal. This project received ethical approval on March 14, 2019, from the CRIR ethics committee and was registered on June 7, 2019, with the US National Library of Medicine at ClinicalTrials.gov (NCT03989752). This study is expected to be completed by spring 2021, with results to follow shortly after.

\section{Discussion}

\section{Overview}

This project innovates by being among the first studies to comprehensively, prospectively, and longitudinally investigate the effects of a wearable robotic exoskeleton-assisted walking program among long-term $\mathrm{WU}_{\mathrm{SCI}}$ who have a very poor prognosis for walking recovery [101]. This study investigates the effects on organic systems, functional capacities, and multifaceted psychosocial factors. This study also investigates the influence of walking program attributes (eg, duration, training frequency, and intensity) on these effects. This project is crucial in strengthening evidence in this field based on hierarchical forms of knowledge creation. This project is also timely, since $\mathrm{WU}_{\mathrm{SCI}}$ are now requesting the democratization of accessibility to this technology during rehabilitation and in the community at a faster rate than evidence is generated and shared with physical activity and rehabilitation professionals, administrators, and policy makers. Strengthened evidence is urgently needed to fill this knowledge gap to some extent and to start informing the decision-making process of these stakeholders regarding the possibility of purchasing wearable robotic exoskeletons as well as developing, implementing, and evaluating activity-based and adapted physical activity programs with wearable robotic exoskeletons in clinical practice (eg, walking program). Moreover, this evidence, once coupled with clients' perspectives, may become key precursors to (1) develop and implement community- and/or home-based walking programs, (2) advocate for policy changes to broaden accessibility to wearable robotic exoskeletons, and (3) propel future larger-scale pragmatic or randomized controlled trials with an appropriate comparator targeting the effectiveness of walking programs with a wearable robotic exoskeleton. Of even greater relevance, it is expected that walking programs with a wearable robotic exoskeleton will reduce impairments (ie, organic systems) and optimize aptitudes, which are expected to positively influence psychosocial outcomes in $\mathrm{WU}_{\mathrm{SCI}}$ and potentially those with other sensorimotor impairments (eg, stroke). In the long term, although not measured in the proposed study, we can hypothesize that indirect societal benefits may become tangible via reduced caregiver burden and reduced health care costs, for example. By optimizing their global health, especially as they age, $\mathrm{WU}_{\mathrm{SCI}}$ will also remain in a state of readiness to benefit from future advances in neural repair, recovery, or rehabilitation technology. Lastly, as some wearable robotic exoskeletons may become approved for home or community use by Health Canada, some $\mathrm{WU}_{\mathrm{SCI}}$ are now 
envisioning their use as personal neuroprostheses for ambulation in their daily lives as a complement to wheelchair mobility in the near future. Still, strengthened evidence is needed to support the prescription and reimbursement processes in order to accelerate uptake of wearable robotic exoskeletons in the community.

Many stakeholders may benefit from this interventional study. For $\mathrm{WU}_{\mathrm{SCI}}$ who have no or very limited walking ability, the walking program with the wearable robotic exoskeleton is not expected to have any reversal effect on their walking capacity without this novel mobility assistive technology. However, this project is relevant since it will generate the first evidence of the anticipated cardiorespiratory, musculoskeletal, and endocrine-metabolic health adaptations upon completion of a walking program with a wearable robotic exoskeleton. For the first time, the extent to which these adaptations translate into beneficial effects on functional capacity will also be verified, as will their effects on health-related quality of life and psychological health. This includes the psychological well-being domain, which was not specifically measured during the feasibility study but was mentioned by the majority of participants. Given the fact that the population of $\mathrm{WU}_{\mathrm{SCI}}$ continues to grow and that they now live longer, these potential beneficial effects are further warranted. The caregiver burden and the potentially costly long-term expenditures associated with adverse health events may also decrease. For rehabilitation professionals, the proposed project is relevant since strengthened evidence regarding the effects of the walking program and the characteristics of the best responders will be generated and will inform clinical decision-making processes or the development of a clinical algorithm for referring individuals with SCIs to a walking program. For rehabilitation program administrators and policy makers, the proposed study is relevant since the evidence generated may further confirm the need for publicly funded clinical and technological infrastructures to create structured programs incorporating walking technologies, such as the wearable robotic exoskeleton, and outcome measures into rehabilitation or adapted physical activity centers. Both program administrators and policy makers will need to work collaboratively and cohesively to develop creative solutions to address this current service gap and engage in transformative improvements. For the research community, this project provides a unique opportunity to create a strong multidisciplinary team of well-established scientists with diverse and complementary academic training as well as clinical and fundamental research expertise. For manufacturers with an interest in wearable robotic exoskeletons, among others, this project is relevant since the input from powered exoskeleton end users (ie, $\mathrm{WU}_{\mathrm{SCI}}$ ) will become available and may enrich the continuous quality improvement process. This process is imperative to further support and accelerate the development of wearable robotic exoskeletons and to reach key commercialization milestones for the technology to become personalized and accessible for $\mathrm{WU}_{\mathrm{SCI}}$ interested in home or community use (ie, neuroprosthesis) in the next decade.

\section{Potential Challenges and Appropriate Mitigation Strategies}

A few potential challenges merit attention:

1. Some potential participants will have insufficient passive range of motion at the lower extremities to engage with the project. These participants will be provided with a 4- to 6-week home-based stretching program, will be reassessed, and may become eligible later.

2. Female $\mathrm{WU}_{\mathrm{SCI}}$ may be underrepresented. Efforts will be made for the sample to be representative of the SCI population and to have women make up $20 \%$ of the sample. However, since the minority of individuals affected by SCIs are female and the sample size is limited $(n=20)$, it is unlikely that statistical analysis by subgroups (ie, male vs female) will be feasible in order to account for potential sex and gender differences. Nonetheless, descriptive statistics will present results separately for women and men whenever indicated.

3. A small number of participants may demonstrate vitamin $\mathrm{D}$ deficiencies [102]. To mitigate this risk, at $\mathrm{T}_{0}$, the equivalent of 1 year of vitamin D3 supplementation will be provided to all participants who are not currently taking supplements. Moreover, all participants will be instructed on healthy balanced diets.

4. Some participants may concurrently engage in extraneous physical activity or may seek cointerventions during the project. Participants will be asked to maintain their customary level of physical activity during the project and to avoid engaging in new cointerventions. Any unintended intervention (ie, contamination or cointervention) that may influence the results will be documented and its effect carefully verified by the research team and possibly considered as a dichotomous variable (ie, present vs absent).

5. Some participants may experience some lower extremity neurorecovery. In the event a participant was to experience neurorecovery (ie, lower extremity motor score of $\geq 20$ on the American Spinal Injury Association Impairment Scale), he or she would be withdrawn from the project and referred for a comprehensive neurological assessment and to an advanced locomotor training program.

\section{Acknowledgments}

This study is funded by the Fonds de recherche du Québec - Santé (grant No. 252532) and the John R Evans Leaders Fund of the Canadian Foundation for Innovation (grant No. 36243). AB received bursaries from the Canadian Institutes of Health Research, the Fonds de recherche du Québec - Santé, the Ordre professionnel de la physiothérapie du Québec and the Faculty of Medicine and Graduate and Postdoctoral Studies of the Université de Montréal for his doctoral studies related to this research project. MAL, ADK, and DHG hold research salary awards from the Fonds de recherche du Québec-Santé. SNM holds a clinical research salary award from the Fonds de recherche du Québec - Santé. 


\section{Conflicts of Interest}

None declared.

\section{References}

1. Noonan VK, Fingas M, Farry A, Baxter D, Singh A, Fehlings MG, et al. Incidence and prevalence of spinal cord injury in Canada: A national perspective. Neuroepidemiology 2012;38(4):219-226 [FREE Full text] [doi: 10.1159/000336014] [Medline: 22555590]

2. Harvey LA, Lin C, Glinsky JV, De Wolf A. The effectiveness of physical interventions for people with spinal cord injuries: A systematic review. Spinal Cord 2009 Mar;47(3):184-195. [doi: 10.1038/sc.2008.100] [Medline: 18725889]

3. Mehrholz J, Kugler J, Pohl M. Locomotor training for walking after spinal cord injury. Spine (Phila Pa 1976) 2008 Oct 01;33(21):E768-E777. [doi: 10.1097/BRS.0b013e3181849747] [Medline: 18827681]

4. Salbach NM, O'Brien K, Brooks D, Irvin E, Martino R, Takhar P, et al. Speed and distance requirements for community ambulation: A systematic review. Arch Phys Med Rehabil 2014 Jan;95(1):117-128.e11. [doi: 10.1016/j.apmr.2013.06.017] [Medline: 23820298]

5. La Fountaine MF, Cirnigliaro CM, Emmons RR, Kirshblum SC, Galea M, Spungen AM, et al. Lipoprotein heterogeneity in persons with spinal cord injury: A model of prolonged sitting and restricted physical activity. Lipids Health Dis 2015 Jul 28;14:81 [FREE Full text] [doi: 10.1186/s12944-015-0084-4] [Medline: 26215870]

6. Ginis KAM, Latimer AE, Arbour-Nicitopoulos KP, Buchholz AC, Bray SR, Craven BC, et al. Leisure time physical activity in a population-based sample of people with spinal cord injury Part I: Demographic and injury-related correlates. Arch Phys Med Rehabil 2010 May;91(5):722-728. [doi: 10.1016/j.apmr.2009.12.027] [Medline: 20434609]

7. Ginis KAM, Arbour-Nicitopoulos KP, Latimer AE, Buchholz AC, Bray SR, Craven BC, et al. Leisure time physical activity in a population-based sample of people with spinal cord injury Part II: Activity types, intensities, and durations. Arch Phys Med Rehabil 2010 May;91(5):729-733. [doi: 10.1016/j.apmr.2009.12.028] [Medline: 20434610]

8. Haisma JA, van der Woude LHV, Stam HJ, Bergen MP, Sluis TAR, Bussmann JBJ. Physical capacity in wheelchair-dependent persons with a spinal cord injury: A critical review of the literature. Spinal Cord 2006 Nov;44(11):642-652. [doi: 10.1038/sj.sc.3101915] [Medline: 16534502]

9. Schneider DA, Sedlock DA, Gass E, Gass G. VO2peak and the gas-exchange anaerobic threshold during incremental arm cranking in able-bodied and paraplegic men. Eur J Appl Physiol Occup Physiol 1999 Sep;80(4):292-297. [doi: 10.1007/s004210050595] [Medline: $\underline{10483798]}$

10. Simmons OL, Kressler J, Nash MS. Reference fitness values in the untrained spinal cord injury population. Arch Phys Med Rehabil 2014 Dec;95(12):2272-2278. [doi: 10.1016/j.apmr.2014.06.015] [Medline: 25007709]

11. Coulson M, Archer D. Practical Fitness Testing: Analysis in Exercise and Sport. London, UK: A\&C Black Publishers; 2009.

12. Warburton D, Eng J, Krassioukov A, Sproule S, The SCIRE Research Team. Cardiovascular health and exercise rehabilitation in spinal cord injury. Top Spinal Cord Inj Rehabil 2007;13(1):98-122 [FREE Full text] [doi: 10.1310/sci1301-98] [Medline: $\underline{22719205]}$

13. Ashe MC, Craven C, Krassioukov A, Eng JJ. Bone health following spinal cord injury. In: Eng JJ, Teasell RW, Miller WC, Wolfe DL, Townson AF, Hsieh JTC, et al, editors. Spinal Cord Injury Rehabilitation Evidence. Version 3.0. Vancouver, Canada: SCIRE Project; 2010:1-26.

14. Ashe MC, Craven C, Eng JJ, Krassioukov A, The SCIRE Research Team. Prevention and treatment of bone loss after a spinal cord injury: A systematic review. Top Spinal Cord Inj Rehabil 2007;13(1):123-145 [FREE Full text] [doi: 10.1310/sci1301-123] [Medline: 22767990]

15. Nelson A, Ahmed S, Harrow J, Fitzgerald S, Sanchez-Anguiano A, Gavin-Dreschnack D. Fall-related fractures in persons with spinal cord impairment: A descriptive analysis. SCI Nurs 2003;20(1):30-37. [Medline: 14626016]

16. Nelson AL, Groer S, Palacios P, Mitchell D, Sabharwal S, Kirby RL, et al. Wheelchair-related falls in veterans with spinal cord injury residing in the community: A prospective cohort study. Arch Phys Med Rehabil 2010 Aug;91(8):1166-1173. [doi: 10.1016/j.apmr.2010.05.008] [Medline: 20684896]

17. Cirnigliaro CM, Myslinski MJ, La Fountaine MF, Kirshblum SC, Forrest GF, Bauman WA. Bone loss at the distal femur and proximal tibia in persons with spinal cord injury: Imaging approaches, risk of fracture, and potential treatment options. Osteoporos Int 2017 Mar;28(3):747-765. [doi: 10.1007/s00198-016-3798-x] [Medline: 27921146]

18. Moore CD, Craven BC, Thabane L, Laing AC, Frank-Wilson AW, Kontulainen SA, et al. Lower-extremity muscle atrophy and fat infiltration after chronic spinal cord injury. J Musculoskelet Neuronal Interact 2015 Mar;15(1):32-41 [FREE Full text] [Medline: 25730650]

19. Elder CP, Apple DF, Bickel CS, Meyer RA, Dudley GA. Intramuscular fat and glucose tolerance after spinal cord injury--A cross-sectional study. Spinal Cord 2004 Dec;42(12):711-716. [doi: 10.1038/sj.sc.3101652] [Medline: 15303112]

20. Buchholz AC, Bugaresti JM. A review of body mass index and waist circumference as markers of obesity and coronary heart disease risk in persons with chronic spinal cord injury. Spinal Cord 2005 Sep;43(9):513-518. [doi: 10.1038/sj.sc.3101744] [Medline: 15824757] 
21. Rajan S, McNeely MJ, Warms C, Goldstein B. Clinical assessment and management of obesity in individuals with spinal cord injury: A review. J Spinal Cord Med 2008;31(4):361-372 [FREE Full text] [doi: 10.1080/10790268.2008.11760738] [Medline: 18959353]

22. Bravo G, Guízar-Sahagún G, Ibarra A, Centurión D, Villalón CM. Cardiovascular alterations after spinal cord injury: An overview. Curr Med Chem Cardiovasc Hematol Agents 2004 Apr;2(2):133-148. [doi: 10.2174/1568016043477242] [Medline: $\underline{15320796]}$

23. Myers J, Lee M, Kiratli J. Cardiovascular disease in spinal cord injury: An overview of prevalence, risk, evaluation, and management. Am J Phys Med Rehabil 2007 Feb;86(2):142-152. [doi: 10.1097/PHM.0b013e31802f0247] [Medline: 17251696]

24. Jensen MP, Hoffman AJ, Cardenas DD. Chronic pain in individuals with spinal cord injury: A survey and longitudinal study. Spinal Cord 2005 Dec;43(12):704-712. [doi: 10.1038/sj.sc.3101777] [Medline: 15968299]

25. Andresen SR, Biering-Sørensen F, Hagen EM, Nielsen JF, Bach FW, Finnerup NB. Pain, spasticity and quality of life in individuals with traumatic spinal cord injury in Denmark. Spinal Cord 2016 Nov;54(11):973-979. [doi: 10.1038/sc.2016.46] [Medline: 27067654]

26. Craig A, Tran Y, Middleton J. Psychological morbidity and spinal cord injury: A systematic review. Spinal Cord 2009 Feb;47(2):108-114. [doi: 10.1038/sc.2008.115] [Medline: 18779835]

27. Rivers CS, Fallah N, Noonan VK, Whitehurst DG, Schwartz CE, Finkelstein JA, RHSCIR Network. Health conditions: Effect on function, health-related quality of life, and life satisfaction after traumatic spinal cord injury. A prospective observational registry cohort study. Arch Phys Med Rehabil 2018 Mar;99(3):443-451 [FREE Full text] [doi: 10.1016/j.apmr.2017.06.012] [Medline: 28732686]

28. Krueger H, Noonan VK, Trenaman LM, Joshi P, Rivers CS. The economic burden of traumatic spinal cord injury in Canada. Chronic Dis Inj Can 2013 Jun;33(3):113-122 [FREE Full text] [Medline: 23735450]

29. Craven C, Balioussis C, Wolfe DL, Hsieh J, Verrier M. Spinal Cord Injury: A Manifesto for Change. Toronto, Canada: Toronto Rehabilitation Institute-University Health Network; 2014. URL: http://scitcs.org/wp-content/uploads/2012/08/ SCITCS-Manifesto.pdf [accessed 2016-02-26]

30. Gibbs JC, Gagnon DH, Bergquist AJ, Arel J, Cervinka T, El-Kotob R, et al. Rehabilitation Interventions to modify endocrine-metabolic disease risk in Individuals with chronic Spinal cord injury living in the Community (RIISC): A systematic review and scoping perspective. J Spinal Cord Med 2017 Nov;40(6):733-747 [FREE Full text] [doi: 10.1080/10790268.2017.1350341] [Medline: 28703038]

31. Soleyman-Jahi S, Yousefian A, Maheronnaghsh R, Shokraneh F, Zadegan SA, Soltani A, et al. Evidence-based prevention and treatment of osteoporosis after spinal cord injury: A systematic review. Eur Spine J 2018 Aug;27(8):1798-1814. [doi: 10.1007/s00586-017-5114-7] [Medline: 28497215]

32. Paleg G, Livingstone R. Systematic review and clinical recommendations for dosage of supported home-based standing programs for adults with stroke, spinal cord injury and other neurological conditions. BMC Musculoskelet Disord 2015 Nov 17;16:358 [FREE Full text] [doi: 10.1186/s12891-015-0813-x] [Medline: 26576548]

33. Federici S, Meloni F, Bracalenti M, De Filippis ML. The effectiveness of powered, active lower limb exoskeletons in neurorehabilitation: A systematic review. NeuroRehabilitation 2015 Nov 02;37(3):321-340. [doi: 10.3233/nre-151265]

34. Nam KY, Kim HJ, Kwon BS, Park J, Lee HJ, Yoo A. Robot-assisted gait training (Lokomat) improves walking function and activity in people with spinal cord injury: A systematic review. J Neuroeng Rehabil 2017 Mar 23;14(1):24 [REE Full text] [doi: 10.1186/s12984-017-0232-3] [Medline: 28330471]

35. Mehrholz J, Kugler J, Pohl M. Locomotor training for walking after spinal cord injury. Cochrane Database Syst Rev 2012 Nov 14;11:CD006676. [doi: 10.1002/14651858.CD006676.pub3] [Medline: 23152239]

36. Morawietz C, Moffat F. Effects of locomotor training after incomplete spinal cord injury: A systematic review. Arch Phys Med Rehabil 2013 Nov;94(11):2297-2308. [doi: 10.1016/j.apmr.2013.06.023] [Medline: 23850614]

37. Gorgey AS, Dolbow DR, Dolbow JD, Khalil RK, Gater DR. The effects of electrical stimulation on body composition and metabolic profile after spinal cord injury--Part II. J Spinal Cord Med 2015 Jan;38(1):23-37 [FREE Full text] [doi: 10.1179/2045772314Y.0000000244] [Medline: 25001669]

38. Gorgey AS, Dolbow DR, Dolbow JD, Khalil RK, Castillo C, Gater DR. Effects of spinal cord injury on body composition and metabolic profile - Part I. J Spinal Cord Med 2014 Nov;37(6):693-702 [FREE Full text] [doi: 10.1179/2045772314Y.0000000245] [Medline: 25001559]

39. Craven BC, Giangregorio LM, Alavinia SM, Blencowe LA, Desai N, Hitzig SL, et al. Evaluating the efficacy of functional electrical stimulation therapy assisted walking after chronic motor incomplete spinal cord injury: Effects on bone biomarkers and bone strength. J Spinal Cord Med 2017 Nov;40(6):748-758 [FREE Full text] [doi: 10.1080/10790268.2017.1368961] [Medline: 28929919]

40. Kohrt WM, Barry DW, Schwartz RS. Muscle forces or gravity: What predominates mechanical loading on bone? Med Sci Sports Exerc 2009 Nov;41(11):2050-2055 [FREE Full text] [doi: 10.1249/MSS.0b013e3181a8c717] [Medline: 19812511]

41. van der Scheer JW, Martin Ginis KA, Ditor DS, Goosey-Tolfrey VL, Hicks AL, West CR, et al. Effects of exercise on fitness and health of adults with spinal cord injury: A systematic review. Neurology 2017 Aug 15;89(7):736-745. [doi: 10.1212/WNL.0000000000004224] [Medline: 28733344] 
42. Hicks AL, Martin Ginis KA, Pelletier CA, Ditor DS, Foulon B, Wolfe DL. The effects of exercise training on physical capacity, strength, body composition and functional performance among adults with spinal cord injury: A systematic review. Spinal Cord 2011 Nov;49(11):1103-1127. [doi: 10.1038/sc.2011.62] [Medline: 21647163]

43. Ginis KAM, Hicks AL, Latimer AE, Warburton DER, Bourne C, Ditor DS, et al. The development of evidence-informed physical activity guidelines for adults with spinal cord injury. Spinal Cord 2011 Nov;49(11):1088-1096. [doi: 10.1038/sc.2011.63] [Medline: 21647164]

44. Nightingale TE, Metcalfe RS, Vollaard NB, Bilzon JL. Exercise guidelines to promote cardiometabolic health in spinal cord injured humans: Time to raise the intensity? Arch Phys Med Rehabil 2017 Aug;98(8):1693-1704. [doi: 10.1016/j.apmr.2016.12.008] [Medline: 28089898]

45. Lajeunesse V, Vincent C, Routhier F, Careau E, Michaud F. Exoskeletons' design and usefulness evidence according to a systematic review of lower limb exoskeletons used for functional mobility by people with spinal cord injury. Disabil Rehabil Assist Technol 2016 Oct;11(7):535-547. [doi: 10.3109/17483107.2015.1080766] [Medline: 26340538]

46. Gagnon DH, Escalona MJ, Vermette M, Carvalho LP, Karelis AD, Duclos C, et al. Locomotor training using an overground robotic exoskeleton in long-term manual wheelchair users with a chronic spinal cord injury living in the community: Lessons learned from a feasibility study in terms of recruitment, attendance, learnability, performance and safety. J Neuroeng Rehabil 2018 Mar 01;15(1):12 [FREE Full text] [doi: 10.1186/s12984-018-0354-2] [Medline: 29490678]

47. Louie DR, Eng JJ, Lam T, Spinal Cord Injury Research Evidence (SCIRE) Research Team. Gait speed using powered robotic exoskeletons after spinal cord injury: A systematic review and correlational study. J Neuroeng Rehabil 2015 Oct 14;12:82 [FREE Full text] [doi: 10.1186/s12984-015-0074-9] [Medline: 26463355]

48. Contreras-Vidal JL, A Bhagat N, Brantley J, Cruz-Garza JG, He Y, Manley Q, et al. Powered exoskeletons for bipedal locomotion after spinal cord injury. J Neural Eng 2016 Jun;13(3):031001. [doi: 10.1088/1741-2560/13/3/031001] [Medline: 27064508]

49. Fisahn C, Aach M, Jansen O, Moisi M, Mayadev A, Pagarigan KT, et al. The effectiveness and safety of exoskeletons as assistive and rehabilitation devices in the treatment of neurologic gait disorders in patients with spinal cord injury: A systematic review. Global Spine J 2016 Dec;6(8):822-841 [FREE Full text] [doi: 10.1055/s-0036-1593805] [Medline: 27853668]

50. Louie DR, Eng JJ. Powered robotic exoskeletons in post-stroke rehabilitation of gait: A scoping review. J Neuroeng Rehabil 2016 Jun 08;13(1):53 [FREE Full text] [doi: 10.1186/s12984-016-0162-5] [Medline: 27278136]

51. Miller L, Zimmermann A, Herbert W. Clinical effectiveness and safety of powered exoskeleton-assisted walking in patients with spinal cord injury: Systematic review with meta-analysis. Med Devices 2016 Mar:455. [doi: 10.2147/mder.s 103102]

52. Esquenazi A, Talaty M, Jayaraman A. Powered exoskeletons for walking assistance in persons with central nervous system injuries: A narrative review. PM R 2017 Jan;9(1):46-62. [doi: 10.1016/j.pmrj.2016.07.534] [Medline: 27565639]

53. Kozlowski AJ, Bryce TN, Dijkers MP. Time and effort required by persons with spinal cord injury to learn to use a powered exoskeleton for assisted walking. Top Spinal Cord Inj Rehabil 2015;21(2):110-121 [FREE Full text] [doi: 10.1310/sci2102-110] [Medline: 26364280]

54. Bach Baunsgaard C, Vig Nissen U, Katrin Brust A, Frotzler A, Ribeill C, Kalke Y, et al. Gait training after spinal cord injury: Safety, feasibility and gait function following 8 weeks of training with the exoskeletons from Ekso Bionics. Spinal Cord 2018 Feb;56(2):106-116. [doi: 10.1038/s41393-017-0013-7] [Medline: 29105657]

55. Baron R, Kneissel M. WNT signaling in bone homeostasis and disease: From human mutations to treatments. Nat Med 2013 Feb;19(2):179-192. [doi: 10.1038/nm.3074] [Medline: 23389618]

56. Alamro RA, Chisholm AE, Williams AMM, Carpenter MG, Lam T. Overground walking with a robotic exoskeleton elicits trunk muscle activity in people with high-thoracic motor-complete spinal cord injury. J Neuroeng Rehabil 2018 Nov 20;15(1):109 [FREE Full text] [doi: 10.1186/s12984-018-0453-0] [Medline: 30458839]

57. Lefeber N, Swinnen E, Kerckhofs E. The immediate effects of robot-assistance on energy consumption and cardiorespiratory load during walking compared to walking without robot-assistance: A systematic review. Disabil Rehabil Assist Technol 2017 Oct;12(7):657-671. [doi: 10.1080/17483107.2016.1235620] [Medline: 27762641]

58. Arazpour M, Samadian M, Bahramizadeh M, Joghtaei M, Maleki M, Ahmadi Bani M, et al. The efficiency of orthotic interventions on energy consumption in paraplegic patients: A literature review. Spinal Cord 2015 Mar;53(3):168-175. [doi: 10.1038/sc.2014.227] [Medline: 25600308]

59. Escalona MJ, Brosseau R, Vermette M, Comtois AS, Duclos C, Aubertin-Leheudre M, et al. Cardiorespiratory demand and rate of perceived exertion during overground walking with a robotic exoskeleton in long-term manual wheelchair users with chronic spinal cord injury: A cross-sectional study. Ann Phys Rehabil Med 2018 Jul;61(4):215-223 [FREE Full text] [doi: 10.1016/j.rehab.2017.12.008] [Medline: 29371106]

60. Chilibeck PD, Guertin PA. Locomotor training and factors associated with blood glucose regulation after spinal cord injury. Curr Pharm Des 2017;23(12):1834-1844. [doi: 10.2174/1381612822666161216120546] [Medline: 27981906]

61. Karelis AD, Carvalho LP, Castillo MJ, Gagnon DH, Aubertin-Leheudre M. Effect on body composition and bone mineral density of walking with a robotic exoskeleton in adults with chronic spinal cord injury. J Rehabil Med 2017 Jan 19;49(1):84-87 [FREE Full text] [doi: 10.2340/16501977-2173] [Medline: 27973679] 
62. Bherer L, Erickson KI, Liu-Ambrose T. A review of the effects of physical activity and exercise on cognitive and brain functions in older adults. J Aging Res 2013;2013:657508 [FREE Full text] [doi: 10.1155/2013/657508] [Medline: 24102028]

63. Sporner ML, Fitzgerald SG, Dicianno BE, Collins D, Teodorski E, Pasquina PF, et al. Psychosocial impact of participation in the National Veterans Wheelchair Games and Winter Sports Clinic. Disabil Rehabil 2009;31(5):410-418. [doi: 10.1080/09638280802030923] [Medline: 18608391]

64. Gagnon DH, Vermette M, Duclos C, Aubertin-Leheudre M, Ahmed S, Kairy D. Satisfaction and perceptions of long-term manual wheelchair users with a spinal cord injury upon completion of a locomotor training program with an overground robotic exoskeleton. Disabil Rehabil Assist Technol 2019 Feb;14(2):138-145. [doi: 10.1080/17483107.2017.1413145] [Medline: 29256640]

65. Dvorak MF, Noonan VK, Fallah N, Fisher CG, Rivers CS, Ahn H, et al. Minimizing errors in acute traumatic spinal cord injury trials by acknowledging the heterogeneity of spinal cord anatomy and injury severity: An observational Canadian cohort analysis. J Neurotrauma 2014 Sep 15;31(18):1540-1547 [FREE Full text] [doi: 10.1089/neu.2013.3278] [Medline: 24811484]

66. Mills EJ, Seely D, Rachlis B, Griffith L, Wu P, Wilson K, et al. Barriers to participation in clinical trials of cancer: A meta-analysis and systematic review of patient-reported factors. Lancet Oncol 2006 Feb;7(2):141-148. [doi: 10.1016/S1470-2045(06)70576-9]

67. Anderson KD, Cowan RE, Horsewell J. Facilitators and barriers to spinal cord injury clinical trial participation: Multi-national perspective of people living with spinal cord injury. J Neurotrauma 2016 Mar 01;33(5):493-499. [doi: 10.1089/neu.2015.4064] [Medline: 26414175]

68. Martin Ginis KA, van der Scheer JW, Latimer-Cheung AE, Barrow A, Bourne C, Carruthers P, et al. Evidence-based scientific exercise guidelines for adults with spinal cord injury: An update and a new guideline. Spinal Cord 2018 Apr;56(4):308-321. [doi: 10.1038/s41393-017-0017-3] [Medline: 29070812]

69. Bass A, Morin SN, Vermette M, Aubertin-Leheudre M, Gagnon DH. Incidental bilateral calcaneal fractures following overground walking with a wearable robotic exoskeleton in a wheelchair user with a chronic spinal cord injury: Is zero risk possible? Osteoporos Int 2020 May;31(5):1007-1011. [doi: 10.1007/s00198-020-05277-4] [Medline: 31932962]

70. Buckley JP, Borg GAV. Borg's scales in strength training: From theory to practice in young and older adults. Appl Physiol Nutr Metab 2011 Oct;36(5):682-692. [doi: 10.1139/h11-078] [Medline: 21977913]

71. He Y, Eguren D, Luu TP, Contreras-Vidal JL. Risk management and regulations for lower limb medical exoskeletons: A review. Med Devices 2017 May; Volume 10:89-107. [doi: 10.2147/mder.s107134]

72. Gagnon DH, Escalona MJ, Vermette M, Carvalho LP, Karelis AD, Duclos C, et al. Locomotor training using an overground robotic exoskeleton in long-term manual wheelchair users with a chronic spinal cord injury living in the community: Lessons learned from a feasibility study in terms of recruitment, attendance, learnability, performance and safety. J Neuroeng Rehabil 2018 Mar 01;15(1):12 [FREE Full text] [doi: 10.1186/s12984-018-0354-2] [Medline: 29490678]

73. Eng JJ, Teasell R, Miller WC, Wolfe DL, Townson AF, Aubut J, The SCIRE Research Team. Spinal cord injury rehabilitation evidence: Methods of the SCIRE systematic review. Top Spinal Cord Inj Rehabil 2007;13(1):1-10 [FREE Full text] [doi: 10.1310/sci1301-1] [Medline: 22767989]

74. Cervinka T, Lynch CL, Giangregorio L, Adachi JD, Papaioannou A, Thabane L, et al. Agreement between fragility fracture risk assessment algorithms as applied to adults with chronic spinal cord injury. Spinal Cord 2017 Nov;55(11):985-993. [doi: $10.1038 /$ sc. 2017.65] [Medline: 28607522]

75. Kirshblum SC, Burns SP, Biering-Sorensen F, Donovan W, Graves DE, Jha A, et al. International standards for neurological classification of spinal cord injury (Revised 2011). J Spinal Cord Med 2013 Jul 19;34(6):535-546. [doi: $10.1179 / 204577211 \times 13207446293695]$

76. Frese EM, Fick A, Sadowsky SH. Blood pressure measurement guidelines for physical therapists. Cardiopulm Phys Ther J 2011;22(2):5-12. [doi: 10.1097/01823246-201122020-00002]

77. Jensen MP, Widerström-Noga E, Richards JS, Finnerup NB, Biering-Sørensen F, Cardenas DD. Reliability and validity of the International Spinal Cord Injury Basic Pain Data Set items as self-report measures. Spinal Cord 2010 Mar;48(3):230-238 [FREE Full text] [doi: 10.1038/sc.2009.112] [Medline: 19786975]

78. Haas BM, Bergström E, Jamous A, Bennie A. The inter rater reliability of the original and of the modified Ashworth scale for the assessment of spasticity in patients with spinal cord injury. Spinal Cord 1996 Sep;34(9):560-564. [doi: 10.1038/sc.1996.100] [Medline: $\underline{8883191]}$

79. Gagnon DH, Roy A, Verrier MC, Duclos C, Craven BC, Nadeau S. Do performance-based wheelchair propulsion tests detect changes among manual wheelchair users with spinal cord injury during inpatient rehabilitation in Quebec? Arch Phys Med Rehabil 2016 Jul;97(7):1214-1218. [doi: 10.1016/j.apmr.2016.02.018]

80. Gagnon DH, Roy A, Gabison S, Duclos C, Verrier MC, Nadeau S. Effects of seated postural stability and trunk and upper extremity strength on performance during manual wheelchair propulsion tests in individuals with spinal cord injury: An exploratory study. Rehabil Res Pract 2016;2016:6842324 [FREE Full text] [doi: 10.1155/2016/6842324] [Medline: 27635262]

81. Gagnon D, Décary S, Charbonneau M. The timed manual wheelchair slalom test: A reliable and accurate performance-based outcome measure for individuals with spinal cord injury. Arch Phys Med Rehabil 2011 Aug;92(8):1339-1343. [doi: 10.1016/j.apmr.2011.02.005] [Medline: 21704977] 
82. Cowan RE, Callahan MK, Nash MS. The 6-min push test is reliable and predicts low fitness in spinal cord injury. Med Sci Sports Exerc 2012 Oct;44(10):1993-2000. [doi: 10.1249/MSS.0b013e31825cb3b6] [Medline: 22617394]

83. Gauthier C, Gagnon D, Jacquemin G, Duclos C, Masani K, Popovic MR. Which trunk inclination directions best predict multidirectional-seated limits of stability among individuals with spinal cord injury? J Spinal Cord Med 2012 Sep;35(5):343-350 [FREE Full text] [doi: 10.1179/2045772312Y.0000000039] [Medline: 23031171]

84. Kirby RL, Rushton PW, Smith C, Routhier F, Best KL, Cowan R, et al. Guide du Programme d'Habiletés en Fauteuil Roulant (WSP-F). Version 5.0 Canadienne-Française [document in French]. Halifax, Canada: Dalhousie University; 2020 Jul 07. URL: https://wheelchairskillsprogram.ca/wp-content/uploads/Guide-du-WSP-F-5.0 07-07-2020.pdf [accessed 2020-08-17]

85. Lobos S, Cooke A, Simonett G, Ho C, Boyd SK, Edwards WB. Assessment of bone mineral density at the distal femur and the proximal tibia by dual-energy $\mathrm{x}$-ray absorptiometry in individuals with spinal cord injury: Precision of protocol and relation to injury duration. J Clin Densitom 2018;21(3):338-346. [doi: 10.1016/j.jocd.2017.05.006] [Medline: 28662973]

86. Cervinka T, Giangregorio L, Sievanen H, Cheung AM, Craven BC. Peripheral quantitative computed tomography: Review of evidence and recommendations for image acquisition, analysis, and reporting, among individuals with neurological impairment. J Clin Densitom 2018;21(4):563-582. [doi: 10.1016/j.jocd.2018.07.003] [Medline: 30196052]

87. Rantalainen T, Nikander R, Heinonen A, Daly RM, Sievanen H. An open source approach for regional cortical bone mineral density analysis. J Musculoskelet Neuronal Interact 2011 Sep;11(3):243-248 [FREE Full text] [Medline: 21885899]

88. ImageJ. URL: https://imagej.net/Welcome [accessed 2016-02-26]

89. Elisha B, Rabasa-Lhoret R, Messier V, Abdulnour J, Karelis AD. Relationship between the body adiposity index and cardiometabolic risk factors in obese postmenopausal women. Eur J Nutr 2013 Feb;52(1):145-151. [doi: 10.1007/s00394-011-0296-y] [Medline: 22209967]

90. Bass A, Brosseau R, Décary S, Gauthier C, Gagnon DH. Comparison of the six-minute propulsion and arm crank ergometer tests to assess aerobic fitness in long-term manual wheelchair users. Am J Phys Med Rehabil 2020:1 (forthcoming). [doi: $10.1097 / \mathrm{phm} .0000000000001534]$

91. Power MJ, Green AM, WHOQOL-Dis Group. Development of the WHOQOL disabilities module. Qual Life Res 2010 May;19(4):571-584. [doi: 10.1007/s11136-010-9616-6] [Medline: 20217246]

92. Jang Y, Hsieh C, Wang Y, Wu Y. A validity study of the WHOQOL-BREF assessment in persons with traumatic spinal cord injury. Arch Phys Med Rehabil 2004 Nov;85(11):1890-1895. [doi: 10.1016/j.apmr.2004.02.032] [Medline: 15520987]

93. The WHOQOL Group. Development of the World Health Organization WHOQOL-BREF quality of life assessment. The WHOQOL Group. Psychol Med 1998 May;28(3):551-558. [doi: 10.1017/s0033291798006667] [Medline: 9626712]

94. Skevington SM, Lotfy M, O'Connell KA, WHOQOL Group. The World Health Organization's WHOQOL-BREF quality of life assessment: Psychometric properties and results of the international field trial. A report from the WHOQOL Group. Qual Life Res 2004 Mar;13(2):299-310. [doi: 10.1023/B:QURE.0000018486.91360.00] [Medline: 15085902]

95. Beck AT, Beamesderfer A. Assessment of depression: The depression inventory. Mod Probl Pharmacopsychiatry 1974;7:151-169. [doi: 10.1159/000395074] [Medline: 4412100]

96. Osman A, Kopper BA, Barrios FX, Osman JR, Wade T. The Beck Anxiety Inventory: Reexamination of factor structure and psychometric properties. J Clin Psychol 1997 Jan;53(1):7-14. [doi: 10.1002/(sici)1097-4679(199701)53:1<7::aid-jclp2>3.0.co;2-s] [Medline: 9120035]

97. Lundgren-Nilsson $\AA$, Jonsdottir IH, Ahlborg G, Tennant A. Construct validity of the Psychological General Well Being Index (PGWBI) in a sample of patients undergoing treatment for stress-related exhaustion: A Rasch analysis. Health Qual Life Outcomes 2013 Jan 07;11:2 [FREE Full text] [doi: 10.1186/1477-7525-11-2] [Medline: 23295151]

98. Grossi E, Groth N, Mosconi P, Cerutti R, Pace F, Compare A, et al. Development and validation of the short version of the Psychological General Well-Being Index (PGWB-S). Health Qual Life Outcomes 2006 Nov 14;4:88 [FREE Full text] [doi: 10.1186/1477-7525-4-88] [Medline: 17105655 ]

99. Dupuy HJ. The Psychological General Well-Being (PGWB) Index. In: Wenger NK, Mattson ME, Furberg CD, Elinson J, editors. Assessment of Quality of Life in Clinical Trials of Cardiovascular Therapies. New York, NY: Le Jacq Publishing; 1984:170-183.

100. Power calculator for continuous outcome superiority trial. Sealed Envelope Ltd. 2012. URL: https://www.sealedenvelope.com/ power/continuous-superiority/ [accessed 2020-08-18]

101. Scivoletto G, Tamburella F, Laurenza L, Torre M, Molinari M. Who is going to walk? A review of the factors influencing walking recovery after spinal cord injury. Front Hum Neurosci 2014;8:141 [FREE Full text] [doi: 10.3389/fnhum.2014.00141] [Medline: 24659962]

102. Hummel K, Craven BC, Giangregorio L. Serum 25(OH)D, PTH and correlates of suboptimal 25(OH)D levels in persons with chronic spinal cord injury. Spinal Cord 2012 Nov;50(11):812-816 [FREE Full text] [doi: 10.1038/sc.2012.67] [Medline: 22710945]

\section{Abbreviations \\ aBMD: areal bone mineral density}


CRIR: Centre de recherche interdisciplinaire en réadaptation du Montréal métropolitain

DXA: dual-energy x-ray absorptiometry

MWESP-Q: Montreal Walking Exoskeleton Satisfaction and Perspectives Questionnaire

pQCT: peripheral quantitative computed tomography

SCI: spinal cord injury

$\mathbf{T}_{\mathbf{0}}$ : control measurement time

$\mathbf{T}_{\mathbf{1}}$ : preintervention measurement time

$\mathbf{T}_{\mathbf{2}}$ : postintervention measurement time

$\mathbf{T}_{\mathbf{3}}$ : retention measurement time

vBMD: volumetric bone mineral density

WU $_{\text {SCI }}$ : wheelchair users with a chronic spinal cord injury

Edited by G Eysenbach; submitted 17.04.20; peer-reviewed by B Smith, T Liyuan; comments to author 17.06.20; revised version received 30.06.20; accepted 07.07.20; published 24.09.20

Please cite as:

Bass A, Aubertin-Leheudre M, Vincent C, Karelis AD, Morin SN, McKerral M, Duclos C, Gagnon DH

Effects of an Overground Walking Program With a Robotic Exoskeleton on Long-Term Manual Wheelchair Users With a Chronic Spinal Cord Injury: Protocol for a Self-Controlled Interventional Study

JMIR Res Protoc 2020;9(9): 19251

URL: http://www.researchprotocols.org/2020/9/e19251/

doi: $10.2196 / 19251$

PMID: 32663160

(C)Alec Bass, Mylène Aubertin-Leheudre, Claude Vincent, Antony D Karelis, Suzanne N Morin, Michelle McKerral, Cyril Duclos, Dany H Gagnon. Originally published in JMIR Research Protocols (http://www.researchprotocols.org), 24.09.2020. This is an open-access article distributed under the terms of the Creative Commons Attribution License (https://creativecommons.org/licenses/by/4.0/), which permits unrestricted use, distribution, and reproduction in any medium, provided the original work, first published in JMIR Research Protocols, is properly cited. The complete bibliographic information, a link to the original publication on http://www.researchprotocols.org, as well as this copyright and license information must be included. 